\title{
NEW DANJOINT HIGH PERFORMANCE OIL LUBRICATED GEAR SPINDLES FOR ESSAR STEEL ALGOMA'S*
}

\author{
Andrea Donadon ${ }^{1}$ \\ Pietro Palma \\ Gianni Tiussi ${ }^{3}$ \\ Massimo Rugo ${ }^{4}$ \\ Morris Codarin ${ }^{5}$ \\ Ferdinando Palagiano 6
}

\begin{abstract}
The upgrading and modernization of rolling mills are playing a key role to improve the steel plant competitiveness in the actual market. Substantially the customer's requests are to broaden the product mix with high mechanical properties steel grades or to increase the plant profitability. The first is usually achieved by increasing the max transmitted torque; the second is achieved with a more reliable and a long life duration machines design. The drive train represents a relevant issue in a rolling mill modernization project. For a constant and reliable power transmission, rolling mills performance and uptime rely on gear spindles which are the most critical equipment of the drive train. Gear spindles are widely used in the drive trains of rolling mills for the steel making, aluminum making and non ferrous alloy industry. Working conditions are extremely tough due to high alternating or pulsating rolling torques in the roughing stands and the high torques and speeds in the finishing stands. Overloads, temperatures and lubrication along with oxide and slag are also critical issues that contribute to create a severe working condition. A new generation of gear spindles featuring continuous oil lubrication has been recently developed in order to deliver the constantly increasing rolling torques aimed to produce harder steel grades and to increase the life time of all critical components. The new series of DANJOINT oil lubricated gear spindles derives from extensive experience, know-how in the drive train technology and on-site testing boasting a dramatic fatigue life increase compared to the standard grease lubricated spindles design. The aim of this paper is to explain the main design features of the New DANJOINT High Performance (HP) oil lubricated gear spindles, the advantages of the continuous oil lubrication on gears and on the most critical spindles components and to show a gears lifetime comparison between oil lubricated and standard grease lubricated spindles.
\end{abstract}

Keywords: Gear spindles; Oil lubrication; Drive train; Hot strip mill; Torque transmission; Crowned gear; Finite element model.

\footnotetext{
Vice President drivetrain technology, Danieli \& C. Officine Meccaniche SpA, Buttrio, Udine, Italy. Senior engineer - mechanics, Danieli \& C. Officine Meccaniche SpA, Buttrio, Udine, Italy.

Senior engineer - mechanics, Danieli \& C. Officine Meccaniche SpA, Buttrio, Udine, Italy.

Project Manager, Danieli \& C. Officine Meccaniche SpA, Buttrio, Udine, Italy.

Design engineer, Danieli \& C. Officine Meccaniche SpA, Buttrio, Udine, Italy.

Managing Director and Vice President - Operations, Danieli Corporation, Cranberry Township, PA, USA.
} 


\section{DISCUSSION}

\subsection{Essar Steel Algoma Overview}

Essar Steel Algoma (formerly Algoma), a company of Essar Steel Holdings Ltd since 2007 , produces hot and cold rolled sheet and plate through a fully integrated steelmaking process with a raw steel production capacity of approximately 2.8 million tons per year. The production of liquid steel is implemented with two 260 ton basic oxygen furnaces by combining molten iron with scrap steel and other required alloy. After the refining process through two metallurgy stations, the electric ladle and the chemical reheat ladle, the plates and coils are produced by means of three lines:

- The Direct Strip Production Complex (DSPC) comprising of a continuous thin slab caster coupled with direct hot strip mill;

- The 166" Plate Mill and the 106" Strip Mills;

- The Cold Mill Complex capable of pickling, reducing, annealing, tempering and slitting.

The DSPC, designed and supplied by Danieli in 1995, is capable of producing strip range of thickness and width respectively between $1.2 \mathrm{~mm}$ and $1.6 \mathrm{~mm}$ and between $810 \mathrm{~mm}$ and $1600 \mathrm{~mm}$. The product mix includes grades such as commercial quality, drawing quality, peritectic, high strength low alloy (HSLA), high carbon grades and formable grades. In a DSPC layout, the one stand non-reversing Roughing mill, coupled with one vertical Edger is linked to a twin strand Thin Slab Caster through two tunnel-type equalizing furnace. Thus, the six stands finishing mill is directly connected to the Roughing Mill through a heated transfer table and the final strip is then conveyed, through the strip cooling equipment, for the final coiling via one or more downcoilers.

Fed by a slabcaster, the 166" Plate Mill and the 106" Strip Mills complete the broad range of products with sheet and light gauge plate to a maximum slit edge width of $2440 \mathrm{~mm}$, carbon and HSLA plate up to $3860 \mathrm{~mm}$ wide.

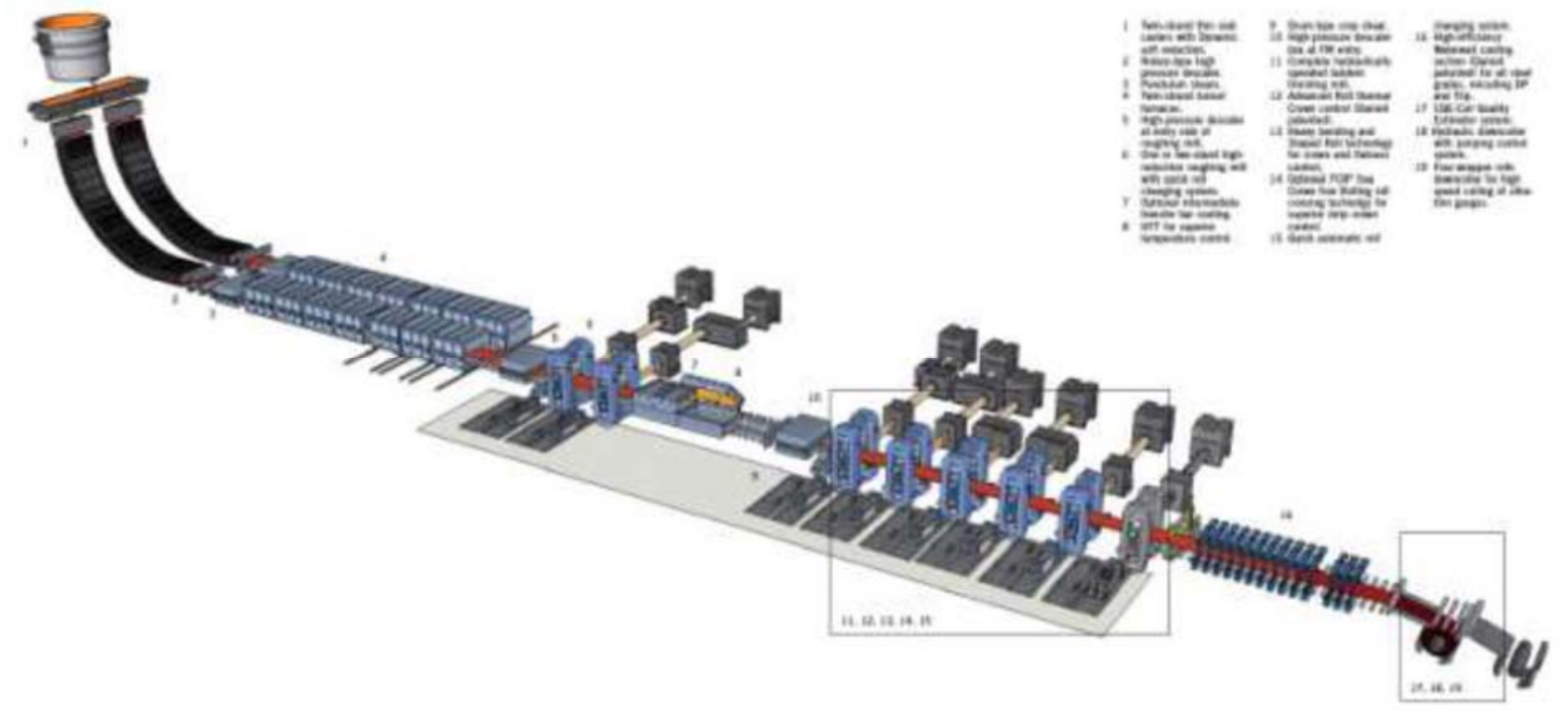

Figure 1. DSPC layout. 


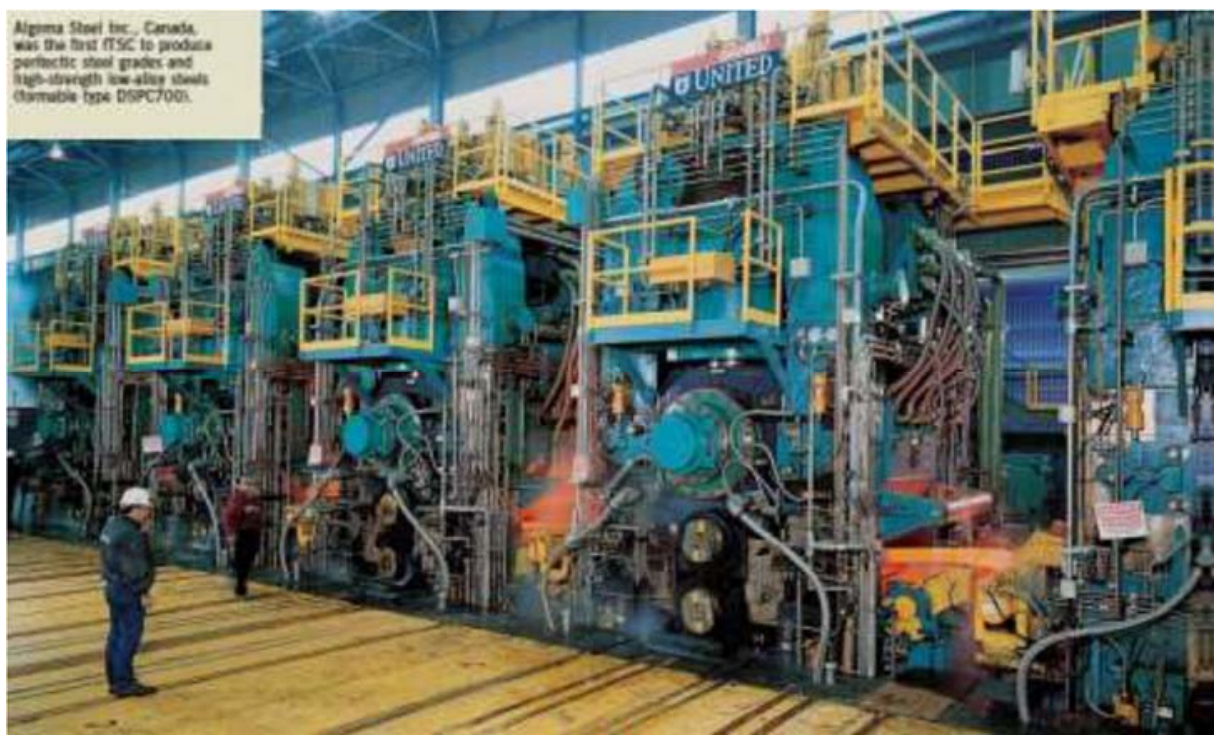

Figure 2. DSPC Finishing mill.

\subsection{Gear Spindles}

Since the beginning the DSPC finishing mill has been running with grease lubricated gear spindle but during the years the spindle design has been reviewed by the supplier without really solving the issues that Essar Algoma is facing so far. The spindles belonging to stands F1/F2 and F5/F6 have been affected by frequent problems resulting so far in consistent maintenance costs that have to be necessarily reduced. For this reason in February 2014 Danieli Service was awarded the upgrading of finishing stands F1, F2, F5 and F6 at Essar Steel Algoma DSPC Hot Strip Mill by providing New DANJOINT HP Oil Lubricated Gear Spindles with a more robust and reliable design than the existing grease lubricated gear spindle.

\subsection{F1/F2 Issues}

The installed spindle roll end outer diameter is $724 \mathrm{~mm}$ with an intermediate gear coupled with a spline connection to the roll hub and meshing with the male gear. The gear material is carburized with a root centering in the male hub gear (root piloting).

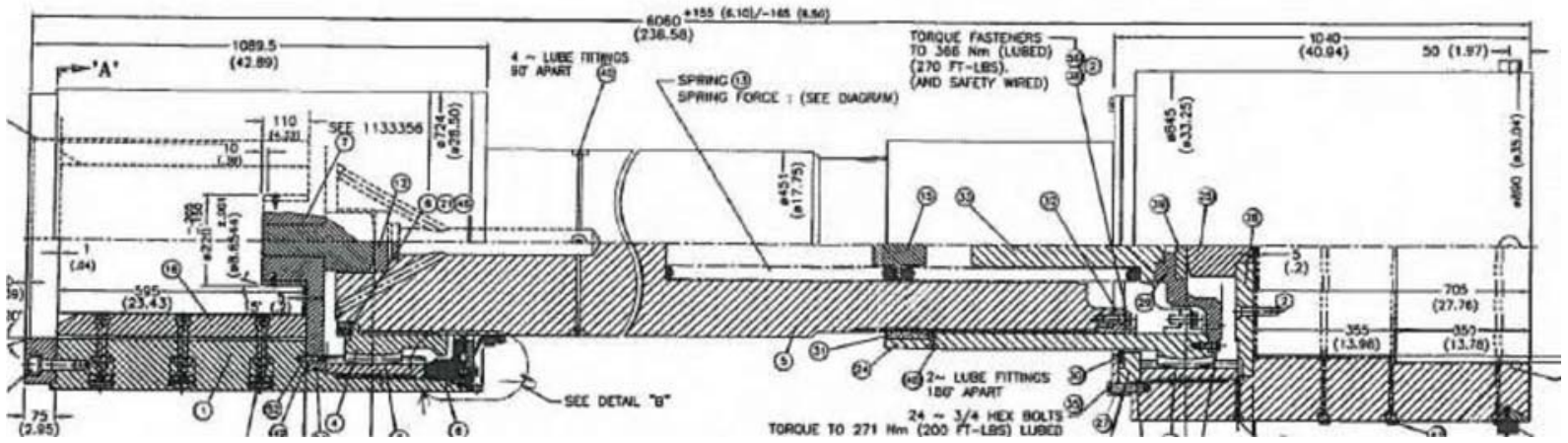

Figure 3. F1/F2 grease lubricated spindles

The first important problem that these spindles have suffered since the start up is a wash out of grease from the roll end spindle assembly, probably due to the high deformations under load, which led to an accelerated wear of the gearing components. With a lubrication breakdown the protective film between the teeth is 
missing and the wear rate increase dramatically as well as heat. Moreover the distortion resulting from carburizing, if not reduced by means of high precision machining, and the high misalignment can reduce considerably the number of teeth engaged under load and consequently increase the stress amount on each tooth. All these factors may result in sub-surface shear and pitting/spalling of the teeth.
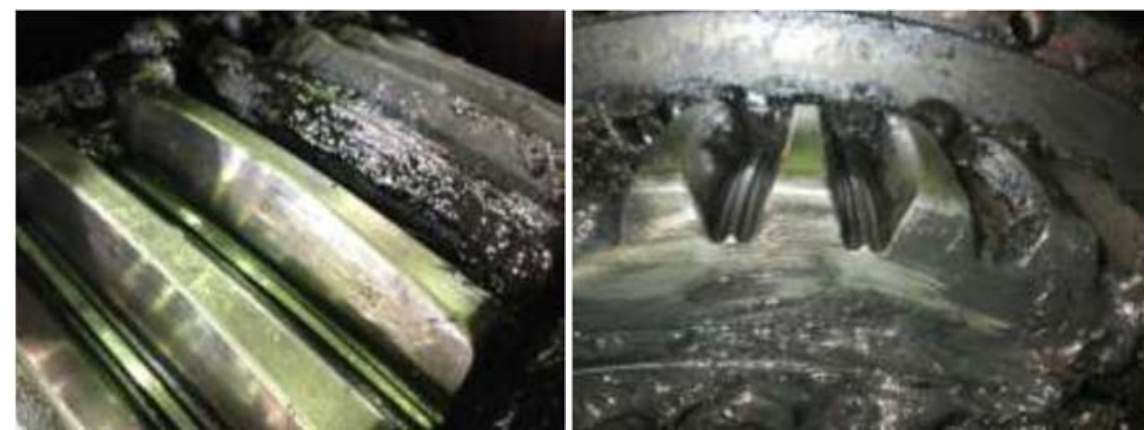

Figure 4. Gear spindle teeth wear.

The intermediate gear teeth had static failures in the "3 and 9 o'clock" position. It is likely that the excessive misalignment of the spindle over the allowable limit during the roll insertion in the hub causes the teeth cracking.

\subsection{F5/F6 Issues}

The installed spindle roll end outer diameter is $600 \mathrm{~mm}$ with an intermediate gear, coupled with a spline connection to the roll hub sleeve, meshing with the male gear.

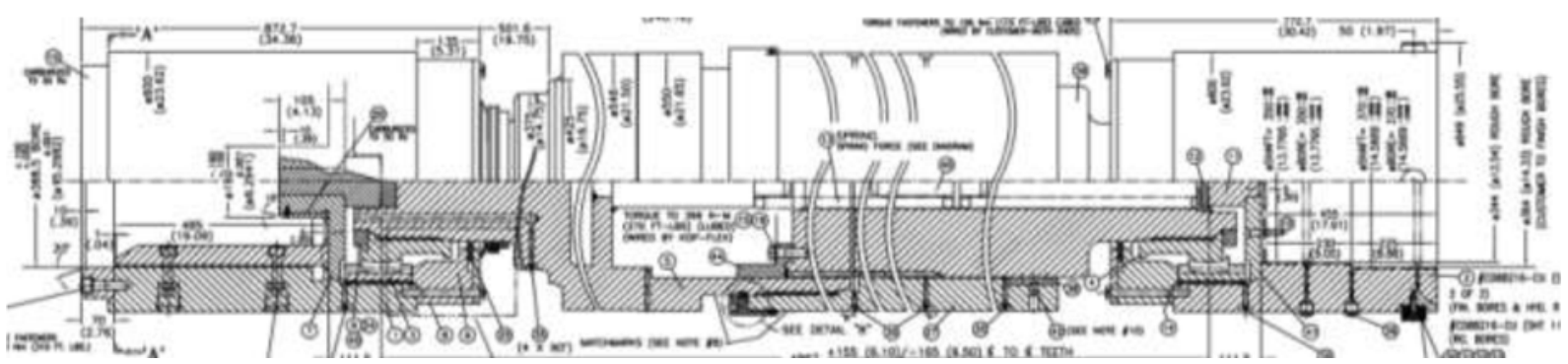

Figure 5. F5/F6 grease lubricated spindles

This spindle has been interested by failure of the bolts in the middle at the spline sleeve retaining ring. The changed design with threaded retaining ring failed as well. The root cause of the failure is expected to be the bending at the middle flex point generated by unexpected radial loads. The spline sleeve inner and outer pilots wear together with the inner bushing of the roll side thrust plate thus introducing an eccentricity in the spindle shaft rotation. In addition to the spindle weight, the additional force created by the eccentricity increases the bending in the telescopic spline section with consequent failures. 


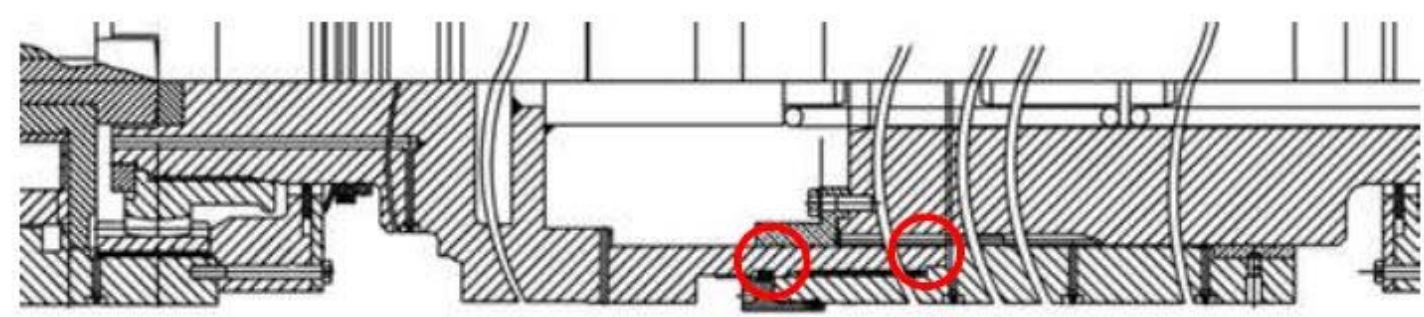

Figure 6. F5/F6 spline sleeve pilots.

\subsection{New DANJOINT HP Oil Lubricated Gear Spindles}

Danieli Service designs and manufactures in their own facilities its DANJOINT HP Oil Lubricated Gear Spindles, for both Danieli's and Competitor hot and cold strip mills main drives. The technical advantages given by oil lubricated gear spindles are:

- Drastic reduction of damages typical of quenched and tempered gears with grease lubrication, like: pitting, abrasion wear bonding and seizure;

- High efficiency in terms of power transmission;

- Low friction between contact surfaces;

- Increased lifetime of geared elements;

- Reduced energy consumption for spindle internal frictions;

- Very high spindle lubrication efficiency;

- Teeth working temperature always below $70^{\circ} \mathrm{C}$;

- Constant cleanliness of the gears contact surface;

- Controlled cooling and oil viscosity;

- New sealing design with no risk for water infiltrations from work rolls into the oil circuit.

The oil lubricated gear spindles differs from the traditional grease lubricated ones by an internal oil lubrication circuit for forced and pressurized oil circulation, with floating sealing and anti-rotation oil feed system. The spindles are provided with a rotary distributor fed by a lubrication system that can be a dedicated one or can be a part of the plant main drives lubrication system. The oil flows inside the spindles, lubricates all mating parts and then it is discharged into an oil collecting box at the drive side. The oil collecting box is provided with a water alarm devices to detect any seals failure. The oil then flows back to the lubrication unit main tank and then it is filtered, cooled and pumped back.
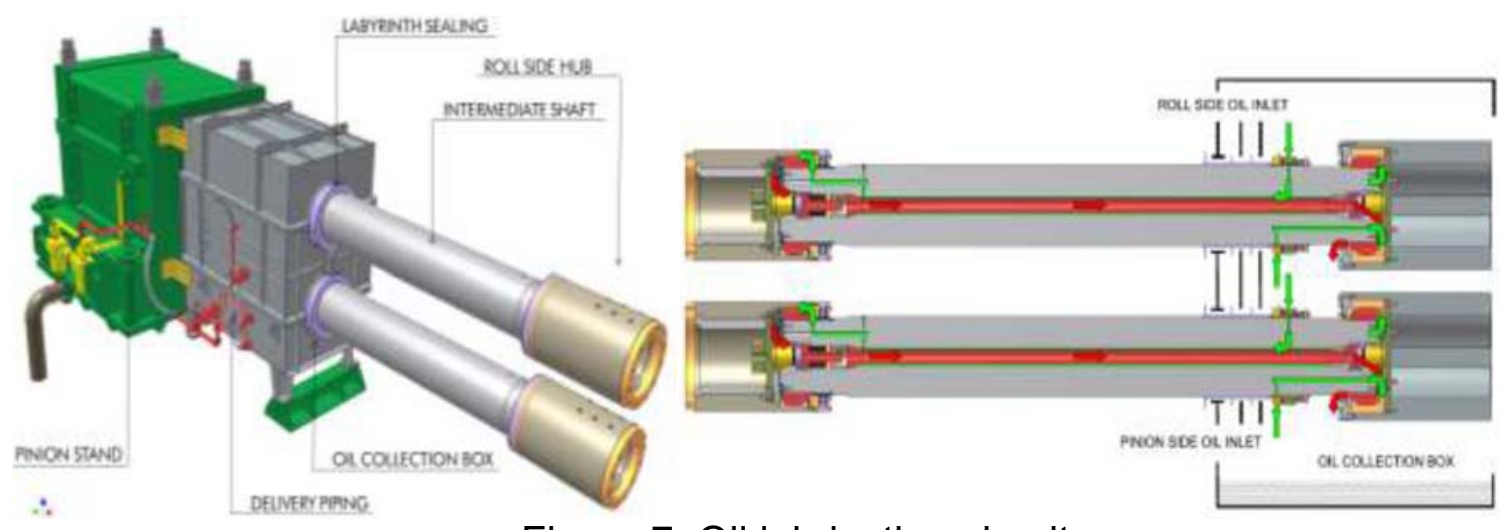

Figure 7. Oil lubrication circuit

Two main versions are manufactured: fixed type and telescopic type. The material used for the gear components are tool steel, carburizing steel and nitriding steel, with 
in-house heat treatments. Every design is conceived to meet the performance requested by each specific application, thus choosing the best combination of materials, heat treatments, tooth profile and crowning becomes of paramount importance, along with the high precision machining to give the desired tolerances. Beside the above mentioned technical aspects, the oil lubricated gear spindles show off the following economical advantages:

- "Easy maintenance" design concept to reduce operation costs;

- Engineered to be quickly interchangeable and reduce downtimes;

- Intermediate geared sleeve to reduce costs of wearing components;

- Drastic reduction of lubricant consumption and relevant storage costs;

- No risk of human error during lubrication that may cause equipment failure;

- No need of lubrication maintenance personnel;

- No need to clean the area around the spindles from grease losses Compared to the grease lubricated gear spindles, the oil lubricated ones give the following environmental advantages:

- No more use of aggressive and extremely polluting greases with hydrocarbons and solid chemical additives;

- Limited environmental pollution;.

- No grease released into atmosphere;

- No more presence of grease or flammable soaps in the spindle area;

- No more daily greasing maintenance procedure.

\subsection{F1/F2 and F5/F6 DANJOINT Designed for Essar Steel Algoma's DSPC}

The design of the new DANJOINT gear spindles is suitable for addressing and avoiding all the issues related with the existing gear spindles. The roll hub outer diameter for F1/F2 and F5/F6 spindles is $725 \mathrm{~mm}$ and $600 \mathrm{~mm}$ respectively. The intermediate gear is coupled with a spline connection to the roll hub sleeve. The gears are manufactured with precision ground carburized material and designed with a tip centering in the male hub crowned gear (tip piloting). The design, machining, materials and heat treatments are optimized in order to double the lifetime of critical components such as geared hubs. For critical applications such as Essar Steel Algoma HSM, the shoot peening is performed in order to improve the fatigue strength of the tooth flank and root. In addition the continuous oil lubrication contributes substantially to lifetime increasing by lowering the temperature in the gear mesh and removing all detrimental particles.

The gear spindle telescopic type with the middle shaft monolithic design makes it possible to get rid of any problems that have affected the spindles belonging to stands F5/F6 due to the spline connection in the middle flex point (i.e. pilots wear, spline sleeve retaining ring failure). The telescopic concept is accommodated at the drive side with the middle shaft capable to shift back and forward. The drive side crowned gear, coupled to the shaft by means of a spline connection, moves together with the shaft thus, the contact pattern on the intermediate gear is distributed along its entire length. 

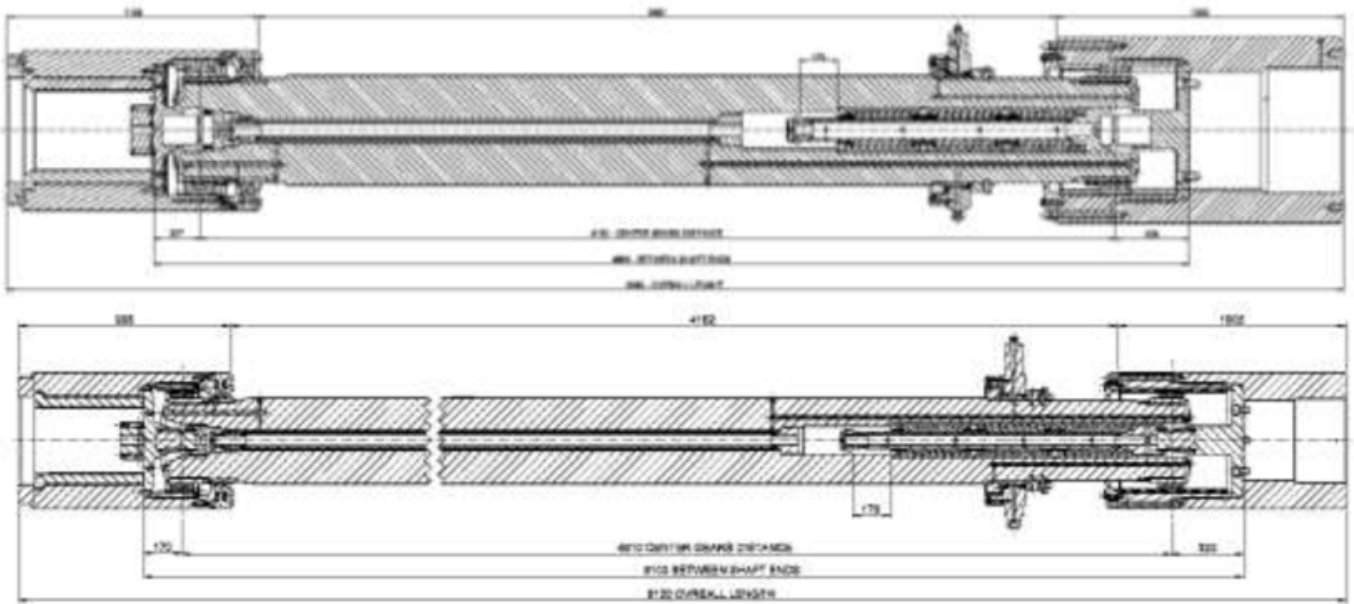

Figure 8. F1/F2 and F5/F6 HP DANJOINT oil lubricated spindles.

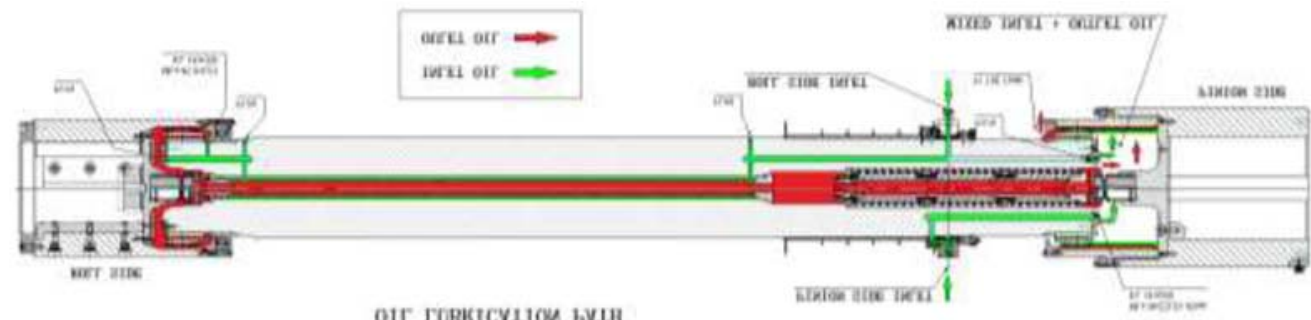

Figure 9. HP DANJOINT continuous oil lubrication path.

The gear components design optimization is performed step by step by means of analytical calculation according to existing bibliography, Finite Element Analysis and experience from previous designs.

The stresses generated in the gear meshing contact are analyzed by building up 3D Finite Element Model of the complete gear components. The model is able to simulate the non linear contact between the teeth with a finer mesh in the contact area, thus obtaining a realistic stress distribution and a deep understanding of the tooth profile behavior under load.
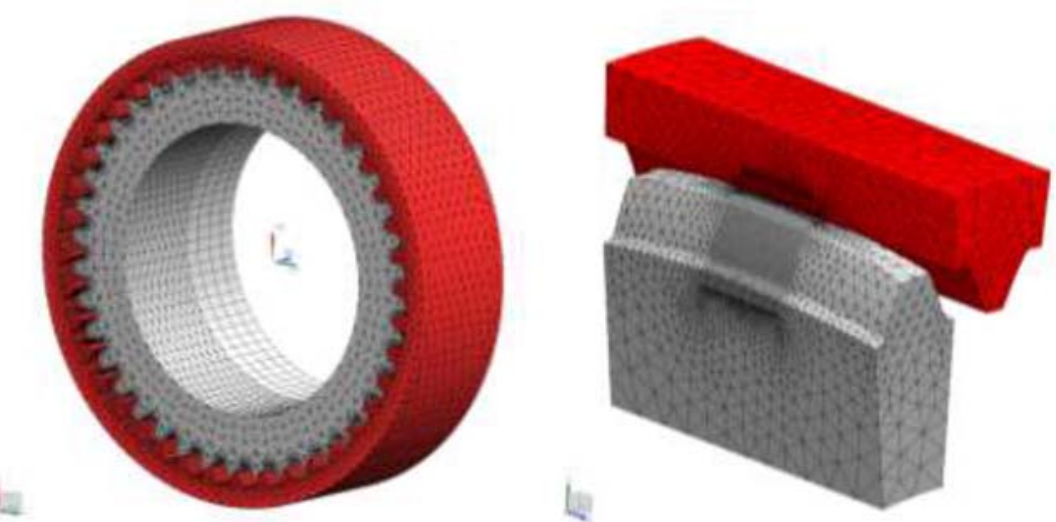

Figure 10. FEM.

The analysis is carried out at different misalignment angles from $0^{\circ}$ to $2^{\circ}$. As the angle of misalignment increases the number of teeth engaged under load becomes lower, as shown in the picture below, and consequently the peak surface stress increases. 

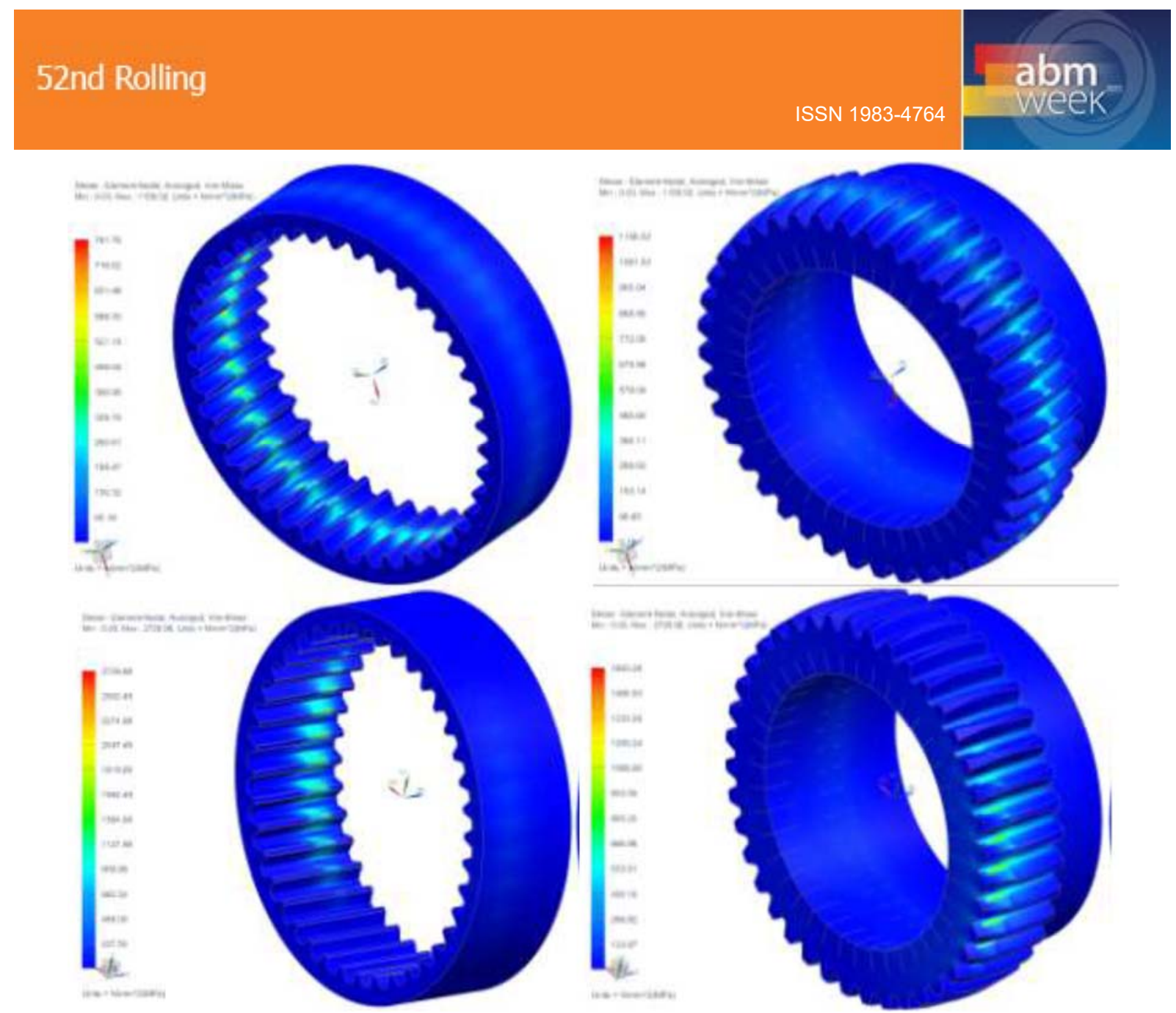

Figure 11. FEA stress results.

To detect also the stress distribution and the maximum stress value beneath the surface, the mesh is refined along the normal direction to the tooth flank.

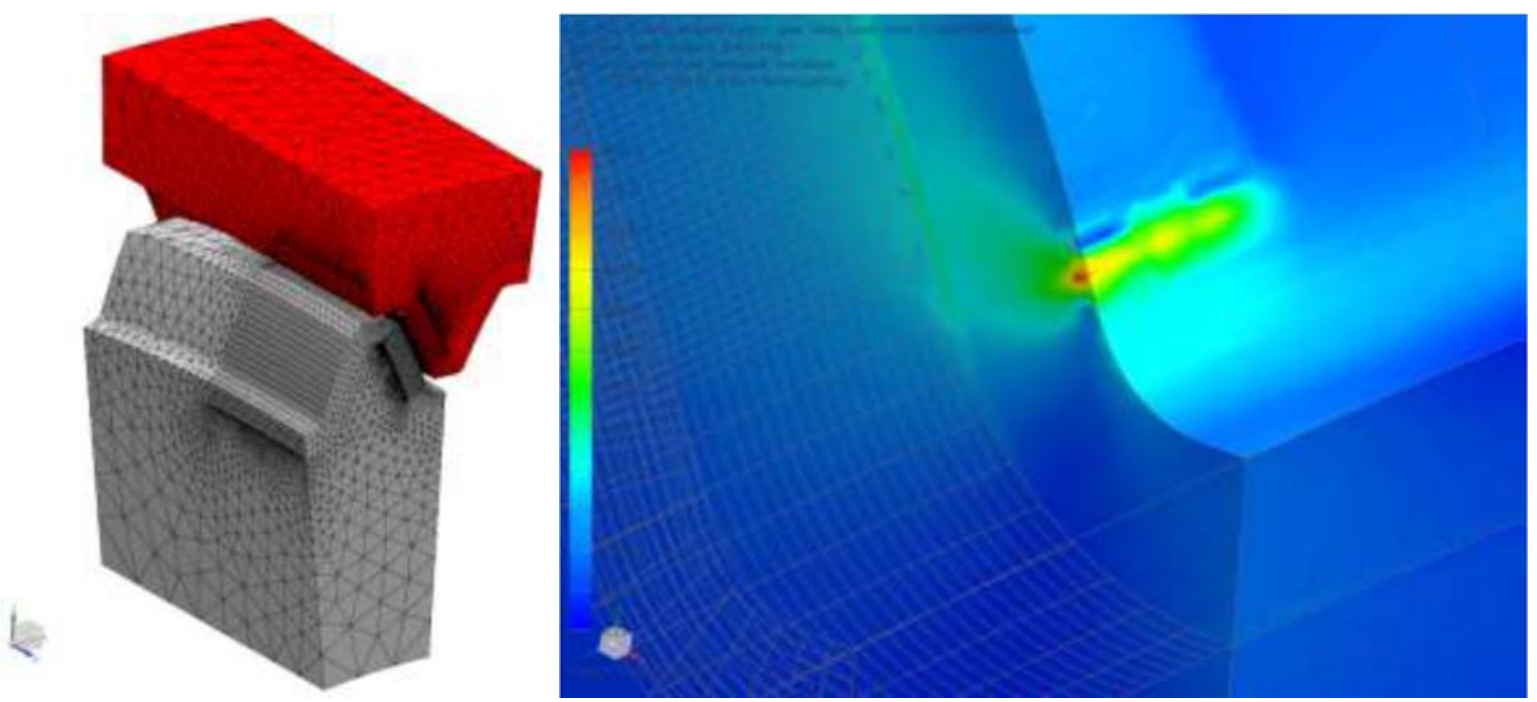

Figure 12. FEA stress distribution

\subsection{Rolling Mills Feedback}

The validation of gear spindle design's features derives from tangible feedback of rolling mills in operation. The oil lubricated gear spindle in operation to date are either first installation or replacement of grease lubricated gear spindles. 
The oil lubricated gear spindles installed on 7-stands finishing mill of a Danieli HSM are exhibiting high performance in terms of reliability and gears components fatigue life. From stand $\mathrm{F} 1$ to $\mathrm{F} 4$ the roll end hub outer diameter is $725 \mathrm{~mm}$ without intermediate gear sleeve. From stand F5 to $\mathrm{F} 7$ the roll end hub outer diameter is 520 $\mathrm{mm}$ with intermediate gear sleeve. All the gears are manufactured

with precision ground carburized steel with a tip centering in the male hub gear (tip piloting).

The HSM started in 2012 and after three years of rolling the spindles have been checked in any critical component. The gear components have been found in a good status with the typical polishing due to gears contact load without any pitting or spalling.

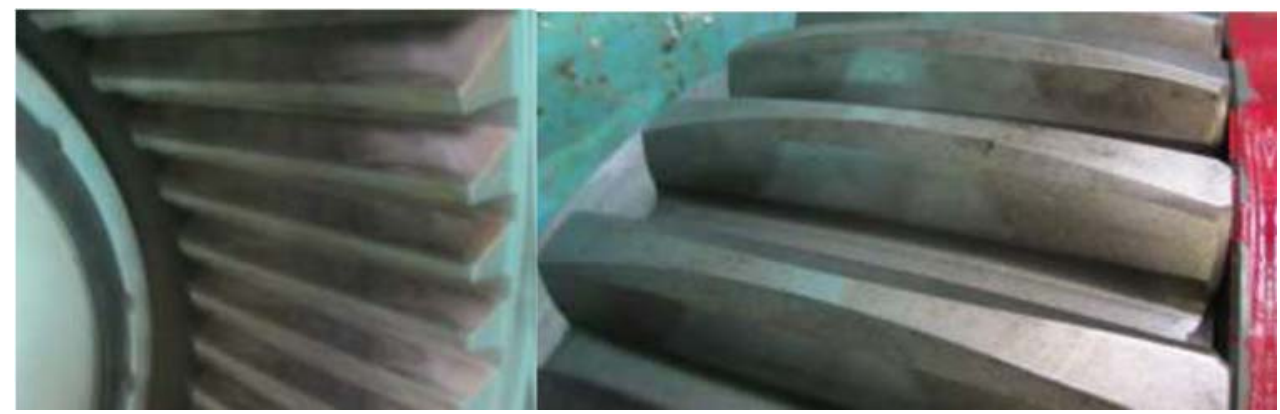

Figure 13. HSM Gear spindle components after 3 years of working.

A proof of the oil lubricated gear spindle achievable performances is also given by a Steckel Mill project with $535 \mathrm{~mm}$ and $475 \mathrm{~mm}$ roll end hub outer diameter and intermediate gear sleeve. The gears are manufactured with tool steel and carburized steel with a tip centering in the male hub gear (tip piloting). The mill has been rolling since two years and the gear components have a typical flank polishing. Compared to brand new crowned gear wheel, the ones that have been working for two years are not showing any damages.

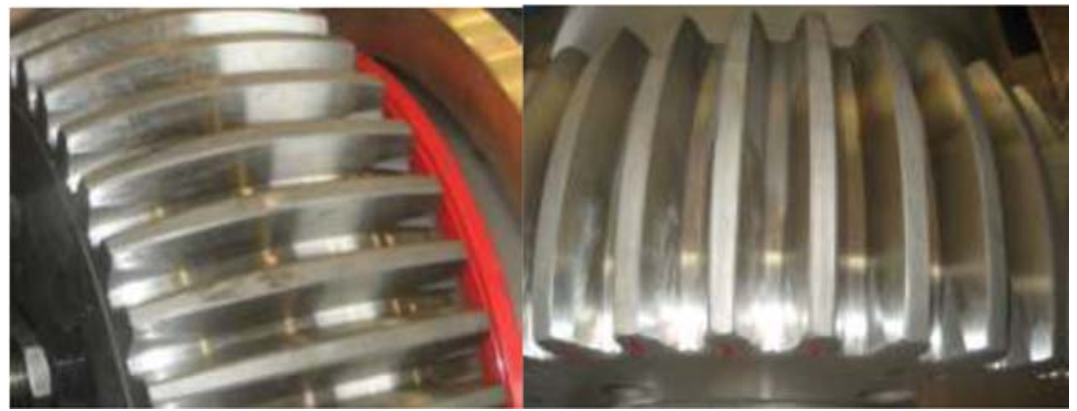

Figure 14. Brand new gear spindle's components for Steckel Mill.

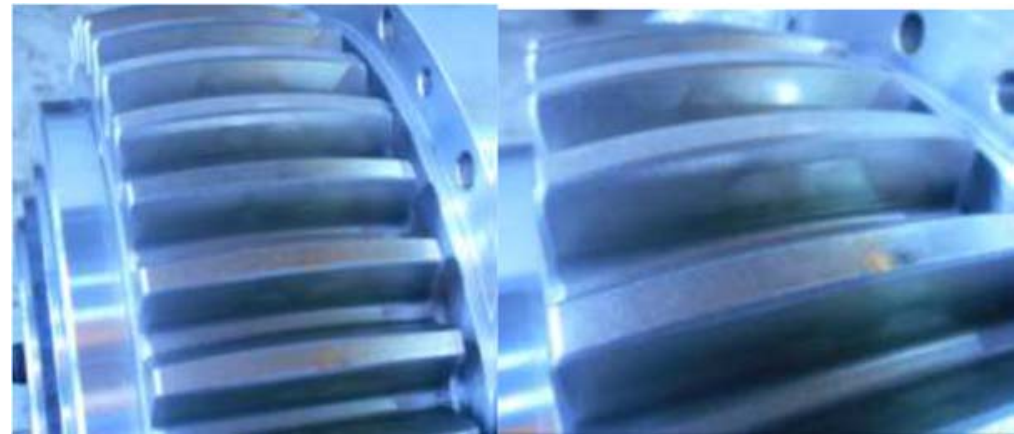

Figure 15. Steckel Mill gear spindle's components after two years of working. 
In addition to technical and economical advantages, the replacement of grease lubricated gear spindles with oil lubricated ones avoids the presence of grease and pollution in the spindle area. Moreover the oil lubrication system (collecting box, piping and instrumentation) can be adapted and integrated into the plant layout without any relevant modification, making it a smart and suitable design for revamps.
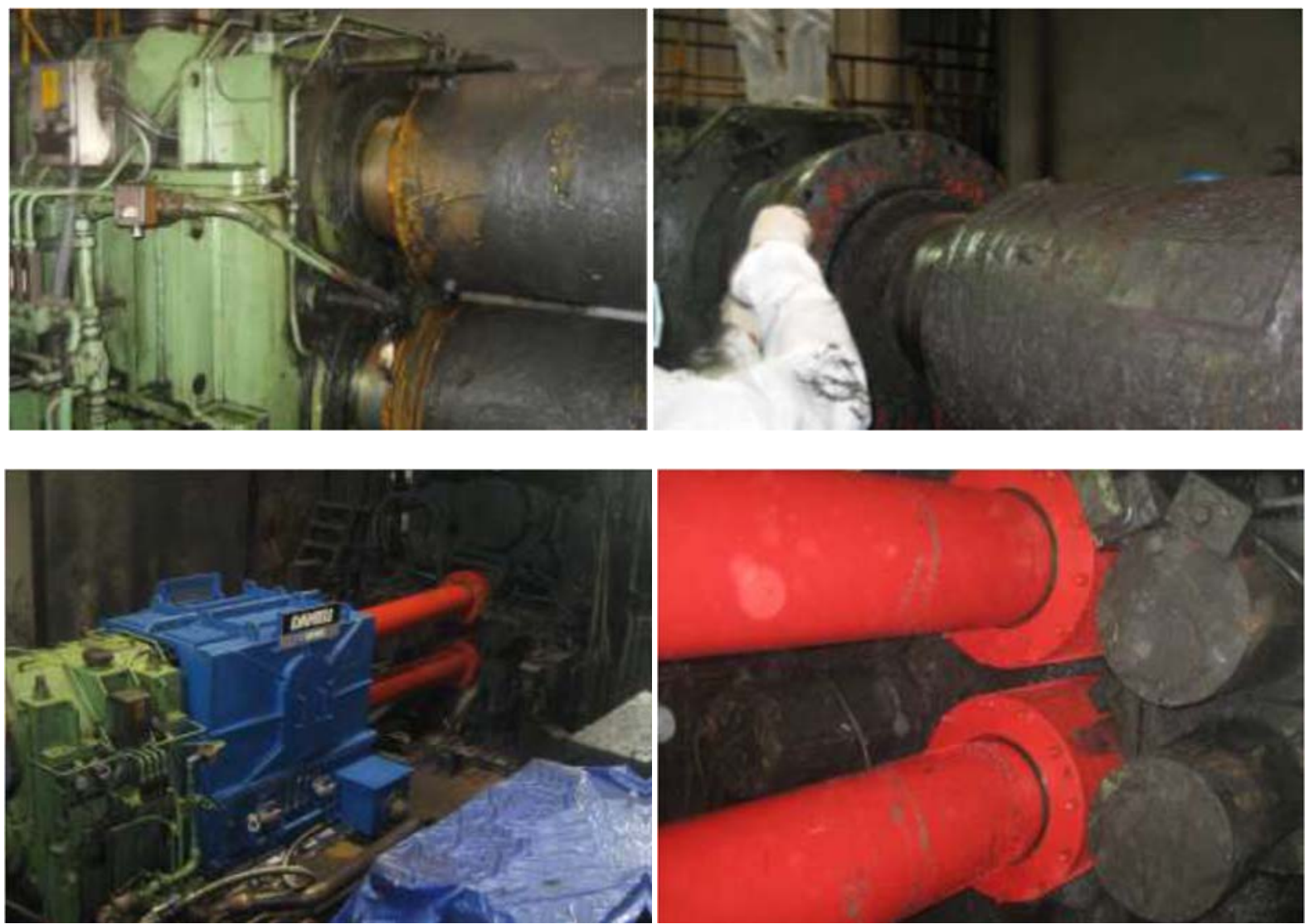

Figure 16. Before and after gear spindle replacement on HSM F7 finishing stand.

One of the latest gear spindle replacement has been done on a F7 stand of HSM finishing mill. The previous grease lubricated gear spindles had the gear components to be replaced every 6 months; instead the oil lubricated gear spindles have not experienced any failure or any part to be replaced after two years of working.

The performances proved by the new oil lubricated gear spindles led the customer to replace the grease lubricated gear spindles of all finshing mill stands.

\section{CONCLUSION}

The continuous customers' demands of reliable rolling mills drive train together with extremely tough working condition made the gear spindle design more challenging over the years. The design complexity relies on the selection of materials, heat treatments and tooth shape, but the right combination of those parameters is a consequence of know-how, experience and on-site testing.

The feedback deriving from on-site installation tip the scale in favour of oil lubricated gear spindles and the years of operation of the currently installed oil lubricated gear spindles flatly ascertain their advantages and performances over the grease lubricated ones. The fatigue life of the gear components can be remarkably increased because of the benefits introduced by oil lubrication such as heat removal 
and gears contact area cleanliness. Moreover the economical and environmental advantages deriving from oil lubrication justify the slightly higher initial investment and the additional auxiliary components with respect to grease lubrication. The fast return of the investment provides tangible benefits for customers and makes this premium technological product definitely attractive on the market. The oil lubrication, along with a new gear design, has proven to be able to dramatically extend the grease lubricated gears life.

\section{BIBLIOGRAPHY}

www.algoma.com.

Innovative quality Strip and Plate Production Technology, Danieli Wean United.

3 J. R. Mancuso, P. Amin, M.A. McGinnity, R. Doan, Gear Spindles for Compact Hot Strip Mills, AISE, Pittsburgh, PA, 2000.

4 C. Cibaldi, I Criteri Di Scelta e Di Trattamento Degli Acciai da Costruzione e da Utensili, Analisi di Cibaldi Dr. Cesare \& C., 2nd edition, 1990.

5 Jon R Mancuso, Couplings and Joints, Design, Selection and Application, Marcel Dekker, 1986.

6 G. Hentriot, Accouplement a Dentures, Institut de l' Engranage et des Transmissions, Bulletin No. 90, May 1987. 